Proceedings of the 2011 Winter Simulation Conference

S. Jain, R.R. Creasey, J. Himmelspach, K.P. White, and M. Fu, eds.

\title{
DEVELOPMENT OF WHOLE-BUILDING ENERGY PERFORMANCE MODELS AS BENCHMARKS FOR RETROFIT PROJECTS
}

\author{
Omer Tugrul Karaguzel \\ Carnegie Mellon University \\ 5000 Forbes Avenue \\ Pittsburgh, PA 15213, USA
}

\author{
Khee Poh Lam \\ Carnegie Mellon University \\ 5000 Forbes Avenue \\ Pittsburgh, PA 15213, USA
}

\begin{abstract}
This paper presents a systematic development process of whole-building energy models as performance benchmarks for retrofit projects. Statistical regression-based models and computational performance models are being used for retrofit projects in industry but these require existing utility data for calibration and validation. Furthermore, a common retrofit design question is the prioritization of choices for replacement of building components and systems yielding optimal energy performance for a given budget. Benchmarking techniques prescribed in current energy standards do not explicitly address such inquiry. Given these constraints and requirements, a benchmarking process is proposed, with categorization of input data, informational sources and relationships between the two. A schematic depiction of the process with data feed-ins from pertinent sources is given. Results indicate diversified use of data sources (for building envelope category) and extensive dependence on information flows external to current energy standards (for thermal zoning, occupancy, lights and equipment, operational schedules, etc.).
\end{abstract}

\section{INTRODUCTION}

Buildings in general and commercial buildings in particular are responsible for about 40\% (38.77 Quads), and $18 \%$ (17.93 Quads) of national primary energy demand, respectively. Corresponding to such amount of energy consumption, commercial buildings in the U.S. share $18 \%$ of national and about $3.7 \%$ of global $\mathrm{CO}_{2}$ emissions (U.S. DOE 2011). Furthermore, new constructions each year add an average of 1.43 billion sq. $\mathrm{ft}$. of new commercial floor space to the existing building stock. Notwithstanding current advancements, a considerable amount of the building stock is composed of buildings that date from periods when energy and environmental concerns are not on the agenda of commercial building sector. About $57 \%$ of current commercial floor space dates back to 1979 and older (37\% of this total is from 1969 and older when there were almost no concerns about energy efficiency in buildings) (U.S. DOE 2011). Furthermore, according to Cort et al. (2009) such commercial buildings can still be in operation at least until 2034-2049 (for buildings from 1969 and younger) considering the median lifetime of 65-80 years. Therefore, retrofitting of existing commercial buildings is a crucial part in achieving environmental sustainability goals set by a number of current initiatives, legislative mandates, or executive orders in the U.S., including the Energy Policy Act of 2005, Energy Independence and Security Act of 2007, Executive Order 13423, U.S. Green Building Council's (USGBC) LEED (Leadership in Energy and Environmental Design) certification scheme, and ASHRAE-supported Architecture 2030 challenge. In addition to energy efficiency gains (and related reductions of $\mathrm{CO}_{2}$ emissions), major retrofitting of historic and other existing buildings provides some other environmental benefits such as avoidance of raw material consumption, conservation of existing green spaces, stabilizing urban density, reuse of infrastructure, and prevention of existing buildings ending up in the waste stream (Denniston 2010). One of the most significant phases of a comprehensive energy retrofit project is benchmarking. This can be simply defined as setting a point of 


\section{Karaguzel and Lam}

reference from which measurements and comparisons can be made (Merriam-Webster 2011). Benchmarking energy use is an integral part of the decision making process of retrofit projects where relative effectiveness of various energy conservation measures are compared and contrasted with respect to a predefined performance goal within the constraints of a project's budget. According to Sartor, Piette, and Tschudi (2000), benchmarking of building energy performance is instrumental in determination of a building's energy efficiency status, establishing targets for improved performance, increasing the accuracy of property value assessments, as well as gaining recognition of exemplary achievement. Furthermore, it draws attention to the need for energy performance benchmarks for identification of best practices pertaining to energy efficiency strategies considered to be deployable during a retrofit project. Relevant literature on benchmarking energy performance of buildings reveals a number of methods that can be classified into two main groups, namely statistical regression-based methods and computational model-based methods.

\subsection{Statistical Regression-Based Benchmarking}

Regression methods of energy benchmarking rely on statistical models developed by the use of an existing data set (from utility data and on-site measurements) to discover possible relationships between a dependent variable (e.g., utility bill) and some independent variables (e.g., weather data, occupancy patterns, operational schedules). Characterization of dominant factors or significant determinants of energy consumption (through sensitivity analysis) is the other objective of this method. For instance, Chung, Hui, and Lam (2006) developed a statistical model based on multivariate linear regression analysis of measured energy use intensities (EUIs) of supermarkets in Hong Kong. This model was capable of explaining the relationships between climate-adjusted EUIs and some explanatory building variables (e.g., building age, occupancy patterns and schedules, HVAC type, and lighting equipment and controls). Utilization of this regression model is in the form of a benchmark table representing an empirical cumulative distribution of EUIs which can be compared with actual EUIs for benchmarking purposes. Dong, Lee, and Sapar (2005) presented a holistic utility bill analysis method for base-lining whole building energy consumption in Singapore. A baseline model was developed by multiple linear regression analysis of collected building and weather data. Correlations are found between energy consumption (monthly utility bill) and a number of climate parameters which are outdoor dry-bulb temperature, relative humidity, and global solar radiation. Results indicated a strong correlation between outdoor dry-bulb temperature and energy consumption at $90 \%$ confidence in the tropical climatic context.

The two highly influential works (in terms of gaining wide scale acceptance throughout energy retrofit and labeling projects in the U.S.) on the development of benchmark models using statistical regression techniques were presented in Sharp (1996) and Hicks and Clough (1998). Sharp's stepwise linear regression model was modified by Hicks and Clough and formed the basis of the ENERGY STAR ${ }^{\circledR}$ benchmarking (U.S. EPA 2011) model based on analysis of a large data set (spread through the nine U.S. census regions) provided by U.S. CBECS (Commercial Building Energy Consumption Survey) (including a random sample data about major building attributes of size, type, HVAC equipment, operation hours, as well as annual energy consumption). Statistically significant explanatory factors of energy use were determined as gross floor area, plug load power density (number of personal computers per 1,000sq.ft.), average weekly operation hours, occupant density (number of workers per 1,000sq.ft.), location (identified by heating and cooling degree days), and percent of gross floor area heated or cooled. After addition of a weather normalization technique and a rating algorithm, the ENERGY STAR ${ }^{\circledR}$ model is turned into an energy rating tool (Portfolio Manager) which is required to obtain ENERGY STAR ${ }^{\circledR}$ label for new buildings. The same rating tool is also required to benchmark energy performance of retrofit projects aiming to receive LEED EBOM (Existing Buildings - Operation \& Maintenance) certification (for both LEED EBOM, Energy \& Atmosphere EA Prerequisite 2: Minimum Energy Efficiency Performance and EA Credit 1: Optimize Energy Efficiency Performance). 


\section{Karaguzel and Lam}

\subsection{Computational Model-Based Benchmarking}

Energy performance benchmarks for retrofit projects can be derived from a notional/hypothetical building definitions determined through the use of integrated mathematical (computational) models. Chimack, Walker, and Franconi (2001) developed a baseline energy model of a 107-year old science museum using the DOE-2.1E simulation program so as to determine current performance level (through estimations of peak heating and cooling loads) and to conduct parametric variations on the same model for the assessment of various retrofit scenarios on HVAC system configurations. One of the most significant parts of their modeling work was to calibrate the building simulation model against measured energy data (utility bill data) within tolerances stated by ASHRAE Guideline 14 so as to achieve a reliable baseline for further evaluations. Pan, Huang, and Wu (2007) developed a DOE-2.1E energy model of a high-rise commercial building in Shanghai after collecting necessary building data (e.g., as-built drawings, system components, operational schedules, a minimum of 12 months historical utility and weather data). The study showed that calibrated simulation models could help identifying specific performance gains from individual energy conservation measures such as decreasing lighting power density, use of economizers, changing system pumps. It was stated that simulation models could also be functional in identifying interactions of these conservation measures with other building systems.

Fumo, Mago, and Luck (2010) used the DOE's EnergyPlus Benchmark models (U.S. DOE EERE 2011) to developed a series of EnergyPlus normalized consumption coefficients (ENECC) that can be used to estimate hourly building energy consumption from utility bill information. This simplified approach provides hourly energy profiles which are not typically available for existing buildings in practice. The authors argued that having pre-determined coefficients (derived from actual data and energy simulation models of typical U.S. buildings) could relieve the user from the burden of performing a detailed dynamic simulation in the first place.

The use of whole-building modeling and simulation techniques forms the basis of model-based energy benchmarking for retrofit projects. Such techniques offer some unique advantages such as generating hourly energy data (through dynamic simulations) which makes it possible to predict dynamic behavior of building systems under changing internal and external conditions. As the term implies whole-building energy modeling ensures integrated building and system analysis for retrofit projects. Such an approach is superior to isolated component assessments and makes it possible to analyze and optimize integrated and coordinated energy savings deduced from interactions of multiple building systems (e.g., daylighting systems, alternative HVAC layouts, envelope improvements, and other passive or active load reduction measures) (Olgyay and Seruto 2010). Furthermore, whole-building energy modeling techniques foster the concept of "performance-based" design where there exists a context-based relationship between form and function instead of causality-based connections (Kalay 1999). This leads to the understanding that different forms can successfully achieve similar functions, similarly different functions can be offered by similar forms. This notion paves the way to deviate from prescriptive methods of code compliance listing comprehensive requirements of individual building components (maximum U-factors for envelope, Ufactors and SHGC values for windows, efficiency factors for water heating and HVAC components) to alternative performance-based compliance paths. Such alternate methods rely on the development of a whole-building energy models as baseline of comparison for a proposed design model which has to reach a certain level of performance for energy rating end certification. A performance-based approach is embraced by ASHRAE Standard 90.1 - 2004 (ASHRAE 2004b) Standard (Energy Standard for Buildings Except Low-Rise Residential Buildings) and establishment of a whole-building energy model is explained in detail in the Performance Rating Method. The same method is also adopted by the IECC (International Energy Conservation Code) and USGBC's LEED rating system where credits are earned by determination of percentage improvements of the performance of a proposed design model over a baseline model in terms of annual energy cost.

Current literature on benchmarking energy performance of buildings for retrofit projects reveals that

both statistical regression-based models (used in ENERGY STAR ${ }^{\circledR}$ labeling and LEED EBOM certification) and calibrated simulation-based models require historical energy use data (either collected from util- 


\section{Karaguzel and Lam}

ity bills or on-site measurements) of various resolutions so as to be functional and reliable. On the other hand, whole-building energy models to be used as benchmarking purposes for new constructions and retrofit projects (following ASHRAE 90.1 Performance Rating Method) require modeling input data information derived from final/proposed design model so as to be functional for comparisons of performance improvements yielding performance-based ratings. However, there is no well-defined approach to develop energy benchmark models for retrofit projects under the following unique conditions and specific requirements:

- Non-existing or non-available historic energy use (utility or measured data).

- Non-existing final/proposed design specifications for applying "back-engineering" (IPMVP 2006) processes where the baseline model derives input information from proposed design model.

- Requirement of the use of dynamic whole-building energy simulation models to provide comparisons of hourly system responses and integrated to have the capability of interactions between different building systems (e.g., lighting, HVAC system, etc.).

The study presented in this paper proposes a development process for whole-building energy models in EnergyPlus v6.0 environment (U.S. DOE BTP 2011) for benchmarking a historical building. Practical issues encountered in the process are discussed and a schematic framework of the model development process is also presented.

\section{CASE STUDY SELECTION}

The study is based on a 42-year old historic building (Building 661) located in Navy Yard Campus, Philadelphia, PA. The 30,000sq.ft. building originally designed to be an exercise center housing a swimming pool and a gymnasium (together with administrative offices and storage spaces) is the subject of a fullspectrum retrofit within the research tasks of the Greater Philadelphia Innovation Cluster (GPIC) for Energy Efficient Buildings (DOE-HUB/GPIC 2011). Building 661 will be retrofitted to transform into an advanced integrated building sciences (living) laboratory housing GPIC activities such as research and development, conferencing, and training programs with administrative offices. The mission of Building 661 within the overall framework of GPIC initiative is to serve as a best practices model for commercial building design, historic adaptive re-use, and energy efficiency innovation through continuous retrofit in Philadelphia and Mid-Atlantic region. Another objective of this retrofit project is to create knowledge that is transferable to the commercial retrofits in its region and nationally. Building has not being used for the last 15 years. There is minimal building-related information and no historical energy performance data available to researchers. Such conditions prohibit the generation and subsequent utilization of statistical regression-based benchmark methods as well as calibrated computational models.

At its current stage, there is no design proposal for the retrofit project available to researchers. This makes it impossible to strictly follow ASHRAE 90.1-2004 Performance Rating Method to develop a complete baseline model due to lack of final/proposed design specifications. On the contrary, a complete whole-building energy model is required so as to gauge the relative effectiveness of various energy conservation and efficiency measures with respect to target performance goals $(50 \%$ energy use reduction with respect to a baseline building). Under such conditions and to meet GPIC project requirements a whole-building energy model of Building 661 is developed within EnergyPlus v6.0 environment which offers an integrated dynamic whole-building energy modeling engine capable of simultaneous loadsystem-plant simulation (as opposed to sequential solvers). The proposed model development process explained in this paper includes the following methodical steps; (1) identification and categorization of modeling input data, (2) specification and explanation of current information sources for the derivation of input data, (3) analysis of simulation inputs with information sources for Building 661, (4) schematic depiction of the framework of the proposed model development process. 


\section{ANALYSIS OF CASE MODEL DEVELOPMENT PROCESS}

\subsection{Input Data Categorization}

The range of data required for the development of a whole-building energy performance model that is fully compatible with dynamic thermal simulations can be classified into ten main categories which can be divided into 61 different sub-categories (Table 1). Further analysis of the entire simulation model developed within the EnergyPlus v6.0 environment revealed that there exist approximately 2500 different data attributes needed to be entered for a complete model. It should be noted that categorization given here is related to the baseline model development process. Proposed or alternative design models (developed for parametric studies) may include increased number of main categories as well as sub-categories since parametric definitions of renewable energy systems (e.g., solar thermal collector systems, or solar electric power generation systems) should be added to the whole-building energy model.

Table 1: Input data categorization.

\begin{tabular}{|c|c|}
\hline Data Category Main & Data Sub-category \\
\hline Building Context & $\begin{array}{l}\text { Geographical location, hourly weather data, design day data, surrounding buildings (solar } \\
\text { obstructions), building orientation (actual), building orientation with rotation (increments of } \\
90^{\circ}, 180^{\circ} \text {, and } 270^{\circ} \text { imposed by ASHRAE } 90.1 \text { standard) }\end{array}$ \\
\hline Building Geometry & Overall building geometry, shading device geometry. \\
\hline $\begin{array}{l}\text { Thermal Zones } \\
\text { (HVAC Blocks) }\end{array}$ & $\begin{array}{l}\text { Thermal zoning layout, adjacency rules (ground contact, inter zonal, adiabatic, exposed), } \\
\text { thermal partitioning (solid walls, air/virtual walls). }\end{array}$ \\
\hline Occupancy & $\begin{array}{l}\text { Occupant densities, occupant metabolic activity type/rate, occupant clothing levels (for } \\
\text { summer and winter seasons). }\end{array}$ \\
\hline Lights and Equipment & $\begin{array}{l}\text { Lighting power density (LPD), equipment power density (EPD), visible and radiant heat } \\
\text { gain fractions for lights, latent and radiant heat gain fractions for equipment, exterior light- } \\
\text { ing level and control type. }\end{array}$ \\
\hline Service Water Heating & $\begin{array}{l}\text { Type, capacity (rated volume), Energy Factor (EF), hot water flow rates for water use } \\
\text { equipments, mains water temperature, hot water delivery temperature. }\end{array}$ \\
\hline Building Envelope & $\begin{array}{l}\text { Window geometry (glazing-to-wall area ratio), window properties (U-factor, Solar Heat } \\
\text { Gain Coefficient - SHGC, visible transmittance }-\mathrm{V}_{\mathrm{T}} \text { ), skylight geometry (skylight-to-roof } \\
\text { area ratio), skylight properties (U-factor, SHGC, } \mathrm{V}_{\mathrm{T}} \text { ), external doors (U-factors), physical } \\
\text { and thermo-physical properties of above and below grade walls, internal walls, roofs, exter- } \\
\text { nal (basement) floors, internal floors and slab-on-grade floors (with construction assem- } \\
\text { blies), construction type and exposed area of internal thermal mass, envelope infiltration } \\
\text { rate. }\end{array}$ \\
\hline Environmental Controls & $\begin{array}{l}\text { Heating, cooling set-point and set-back temperatures, minimum outdoor air ventilation } \\
\text { rates, limitations on daylight controls (daylight illuminance set-points, and visual comfort } \\
\text { set-point which is maximum allowable discomfort glare index) }{ }^{2} \text {. }\end{array}$ \\
\hline \multirow{3}{*}{ HVAC System } & $\begin{array}{l}\text { HVAC System Type } \\
\text { ASHRAE 90.1-Appendix G HVAC type and economizer selection, economizer high limit } \\
\text { shut-off temperature. }\end{array}$ \\
\hline & $\begin{array}{l}\text { HVAC System Sizing Parameters } \\
\text { Sizing factors (for heating and cooling), design supply air temperatures and supply air hu- } \\
\text { midity (for heating and cooling). }\end{array}$ \\
\hline & $\begin{array}{l}\text { HVAC Component Parameters } \\
\text { Fan operation type (continuous/cycling), fan efficiencies, zone/terminal/air loop fan pres- } \\
\text { sure rise values, cooling coil rated COP, heating coil gas burner efficiency, rated pump } \\
\text { heads, minimum and maximum supply air temperatures. }\end{array}$ \\
\hline Operational Schedules & $\begin{array}{l}\text { Building schedules (for occupant density, activity, and clothing, lighting, equipment, enve- } \\
\text { lope infiltration rate, water use equipments), environmental control schedules (heating and } \\
\text { cooling thermostats), HVAC system operational availability schedules (for air handling } \\
\text { units, fans, pumps, coils, boilers and chillers). }\end{array}$ \\
\hline \multicolumn{2}{|l|}{ Note: } \\
\hline
\end{tabular}




\section{Karaguzel and Lam}

Baseline modeling input analysis also revealed that although generation of building geometry requires largest number of input data points (representing x-y-z coordinates of each vertex of each building surface), largest number of discrete input data sub-category is observed for building envelope and HVAC system definitions. As the number of sub-categories for a model component increases the number of possible informational sources needed to derive necessary input data also increases. Building geometry can be defined by a large number of input data points however there is single information source required to derive such data input (e.g., as-built drawings as in the case of Building 661). On the contrary, so as to define a complete building envelope model, necessary information should be derived from multiple information sources (as analyzed in the following sections).

\subsection{Specification and Explanation of Information Sources}

The unique situation of deep retrofit projects for building cases lacking historic energy use data as well as non-existent proposed design specifications requires derivation of necessary input data for baseline whole-building energy models from multiple information sources.

Multiplicity of sources has unavoidable and profound impacts on time and effort spent on baseline model development during initial phases of performance-based energy retrofit projects. Therefore, it will be helpful to classify and explain possible information sources in addition to input data categorization as mentioned above. Detailed analysis of whole-building model development process for the Building 661 case reveals a total of five different information source categories which can be listed as (1) relevant building standards, (2) reference whole-building energy models, (3) external whole-building energy model generators, (4) latest project documents and survey data, (5) weather data sources (Table 2).

Table 2: Information source categorization.

\begin{tabular}{|l|l|l|}
\hline \multicolumn{1}{|c|}{ Source Category } & \multicolumn{1}{|c|}{ Information Source } & \multicolumn{1}{c|}{ Explanation } \\
\hline \multirow{3}{*}{ Building standards } & $\begin{array}{l}\text { ASHRAE 90.1 2004 Standard } \\
\text { (Energy Standard for Building Except Low-Rise } \\
\text { Residential Buildings) (ASHRAE 2004b) }\end{array}$ & $\begin{array}{l}\text { Building standard providing minimum energy- } \\
\text { efficient requirements and criteria for determin- } \\
\text { ing compliance with these requirements adopted } \\
\text { for baseline whole-building energy models. }\end{array}$ \\
\cline { 2 - 3 } & $\begin{array}{l}\text { ASHRAE 62.1 2004 Standard } \\
\text { (Ventilation for Acceptable Indoor Air Quality) } \\
\text { (ASHRAE 2004a) }\end{array}$ & $\begin{array}{l}\text { Building standard specifying minimum ventila- } \\
\text { tion rates and indoor air quality acceptable to } \\
\text { human occupants. }\end{array}$ \\
\hline Reference models & $\begin{array}{l}\text { The U.S. Department of Energy (DOE) Com- } \\
\text { mercial Reference Building Models } \\
\text { (U.S. DOE EERE 2011) }\end{array}$ & $\begin{array}{l}\text { Complete EnergyPlus models representing typi- } \\
\text { cal (approximately 70\% of) U.S. commercial } \\
\text { building stock from 16 different climate zones. }\end{array}$ \\
\hline $\begin{array}{l}\text { External model } \\
\text { generators }\end{array}$ & $\begin{array}{l}\text { The U.S. DOE - NREL (National Renewable } \\
\text { Energy Laboratory) EnergyPlus Example File } \\
\text { Generator (EEFG) Tool (U.S. DOE NREL 2011) }\end{array}$ & $\begin{array}{l}\text { Web-based tool generating customized (via } \\
\text { high-level input parameters) EnergyPlus models } \\
\text { with default input details in compliance with } \\
\text { building energy standards. }\end{array}$ \\
\hline $\begin{array}{l}\text { Project documents }- \\
\text { Survey Data }\end{array}$ & Specific to building case & $\begin{array}{l}\text { As-built architectural, structural, MEP drawings } \\
\text { and specifications from project archives as well } \\
\text { geometric data obtained from site surveys (e.g., } \\
\text { laser scanning). }\end{array}$ \\
\hline Weather Data & EnergyPlus weather data (U.S. DOE BTP 2011) & $\begin{array}{l}\text { Weather data in EnergyPlus format derived } \\
\text { from Typical Meteorological Year 3 (TMY 3) } \\
\text { data set for 1020 U.S. locations. }\end{array}$ \\
\hline
\end{tabular}

The baseline model for Building 661 is developed by following the rules and requirements as explained in Performance Rating Method of ASHRAE 90.1 2004 standard. Minimum outdoor air flow rate entries are specified for different building space use types based on ASHRAE 62.12004 standard. The U.S. DOE Reference Models (U.S. DOE EERE 2011) are utilized to derive model input data which are not stated in the above mentioned building standards. Such data are mostly required for categories of thermal zones, occupancy data, lights and equipment, service water heating system, HVAC system, and related operational schedules. EEFG tool (U.S. DOE NREL 2011) is used to generate specific input data 


\section{Karaguzel and Lam}

for building envelope category (slab-on-grade floor construction assemblies), and HVAC system (pressure rise values for fans of terminal units). Project documents and survey data are used for generation and calibration of geometric definition of the baseline model. Hourly weather data that is compatible for running annual and dynamic EnergyPlus v6.0 simulations as well as design day weather data for performing HVAC system sizing calculations (to specify design parameters through auto-sizing) are also needed for baseline retrofit models. Detailed analysis of such links between model input data and their reference (information source) for Building 661 retrofit case are given below.

\subsection{Analysis of Simulation Inputs}

Instead of giving an exhaustive list of all possible simulation inputs for Building 661 case, a focused analysis is pursued here with emphasis on input data categories which are unique to baseline simulation models of historic buildings in the sense that such data cannot be derived through back-engineering processes or identified through the use of historic or measured field data. Majority of the critical input data are observed for categories of thermal zones (HVAC blocks), occupancy, lights and equipment, and service water heating (SWH) (Table 3).

Table 3: Input data analysis for thermal zones, occupancy, lights and equipment, and SWH.

\begin{tabular}{|c|c|c|}
\hline Simulation Input Category & Input Value/Attribute & Data Reference \\
\hline Thermal zones (HVAC blocks) & $\begin{array}{l}\text { Simple perimeter and core zoning approach. A } \\
\text { total of } 12 \text { thermal zones are defined ( } 10 \text { perime- } \\
\text { ter }+2 \text { core zones) }\end{array}$ & $\begin{array}{l}\text { Inferred from DOE Reference } \\
\text { Model (Medium office) }\end{array}$ \\
\hline Occupancy & $\begin{array}{l}18.58 \mathrm{~m}^{2} / \text { person }\left(0.053 \text { person } / \mathrm{m}^{2}\right), \text { Radiant Frac- } \\
\text { tion }=0.3 \text {, Metabolic Activity }=\text { Light Office } \\
\text { Work, Metabolic Rate }=120 \mathrm{~W} / \text { person, Winter } \\
\text { Clothing }=1.0 \text { clo, Summer Clothing }=0.50 \mathrm{clo}\end{array}$ & \multirow{2}{*}{$\begin{array}{l}\text { DOE Reference Model } \\
\text { (Medium Office) }\end{array}$} \\
\hline Lights and Equipment & $\begin{array}{l}\text { Lighting Power Density }(\mathrm{LPD})=10.76 \mathrm{~W} / \mathrm{m}^{2} \text {, } \\
\text { Radiant Fraction }=0.4 \text {, Visible Fraction }=0.2 \text {, } \\
\text { Suspended Luminaire type } \\
\text { Equipment Power Density }(\text { EPD })=10.76 \mathrm{~W} / \mathrm{m}^{2} \text {, } \\
\text { Latent Fraction }=0.0, \text { Radiant Fraction }=0.5\end{array}$ & \\
\hline Service Water Heating & $\begin{array}{l}\text { Gas storage water heater } \\
100 \text { gallon rated volume, natural gas fuel source } \\
\text { Minimum Energy Factor }(\mathrm{EF})=0.62-0.0019 \mathrm{~V} \\
\mathrm{~V}=\text { Rated volume in gallons, } \mathrm{EF}=0.43\end{array}$ & $\begin{array}{l}\text { Type, rated volume and fuel } \\
\text { source from DOE Reference } \\
\text { models, EF from ASHRAE } 90.1 \\
2004 \text { (Table } 7.8 \text { Page 58) }\end{array}$ \\
\hline
\end{tabular}

Since there is no proposed design model for Building 661 retrofit case at this moment, the thermal zones are inferred from DOE reference models which follow simple perimeter and core zoning approach. Perimeter zone boundary is specified about $5.0 \mathrm{~m}$ from external walls facing each cardinal direction (Figure 1).

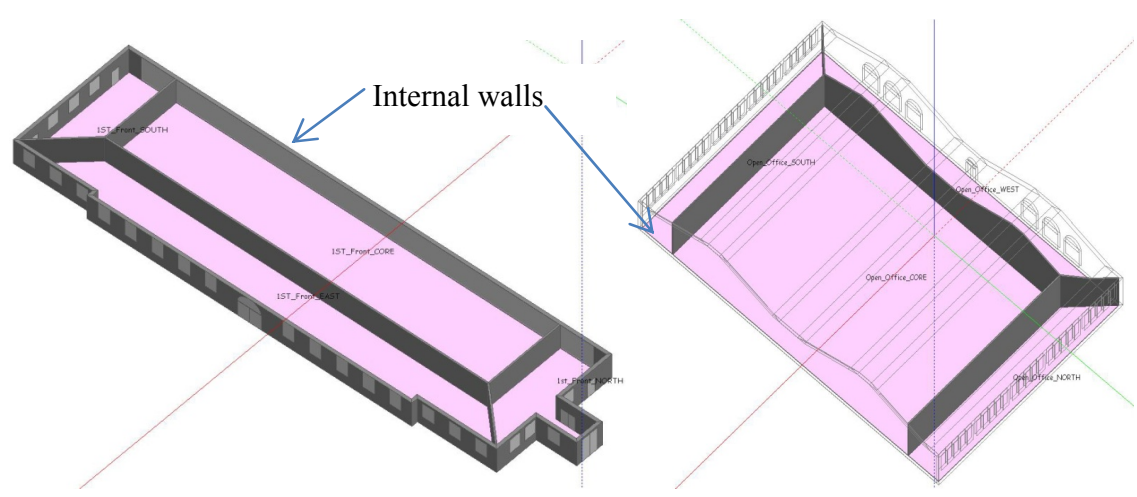

Figure 1: Thermal zoning layout for Building 661. 


\section{Karaguzel and Lam}

Furthermore, due to the lack of information about final occupancy levels for the retrofit project yields occupancy assumptions derived from the DOE Reference Models indicating typical values for the U.S. office buildings. LPDs and EPDs with their respective heat gain fractions are assumed to be the same as those of the DOE Reference Models. The same approach is followed for type, capacity (rated volume) and fuel source of the SHW (Service Water Heating)equipment except its EF which is derived from the related table of ASHRAE 90.1 - 2004 standard. Specification of baseline model input data for historic buildings regarding building envelope sub-data categories do not differ from baseline models for new constructions except for the sub-categories listed below (Table 4). ASHRAE 90.1-2004 does not provide guidance on specification of such model data inputs. Therefore, combined use of DOE Reference Models and a sample building model developed by the use of EEFG Tool becomes necessary to fully define all components of the building envelope.

Table 4: Input data analysis for building envelope category

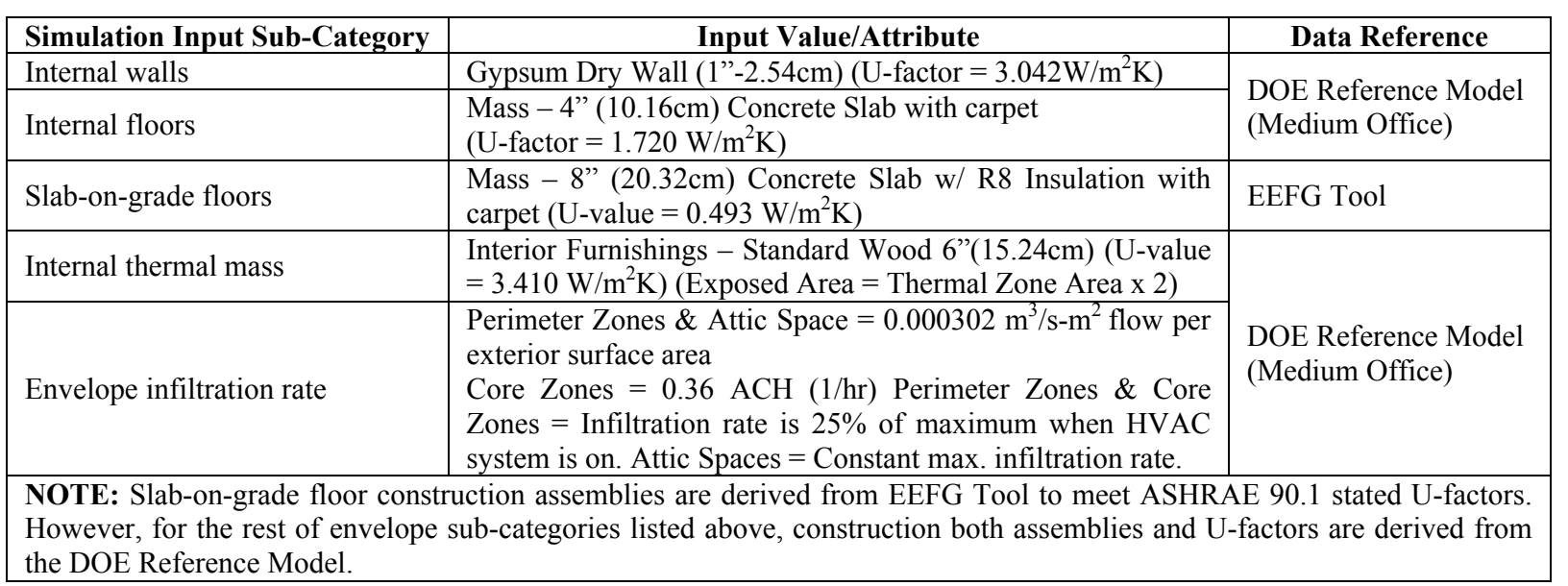

Baseline model assumptions for all components of environmental controls category can be derived from ASHRAE standards of 90.1 and 62.1without recourse to any other information source. Although the HVAC system type, and sizing parameters, and majority of system component parameters can be derived from ASHRAE 90.1 - 2004, several HVAC design parameters given in Table 5 need to be obtained separately from other sources.

Table 5: Input data analysis for HVAC system.

\begin{tabular}{|l|l|l|}
\hline Simulation Input Sub-Category & \multicolumn{1}{|c|}{ Input Value/Attribute } & \multicolumn{1}{c|}{ Data Reference } \\
\hline Fan operation parameters & $\begin{array}{l}\text { Cycling run time }=1800 \mathrm{sec} \\
\text { Cycling thermostat tolerance }=2^{\circ} \mathrm{C}\end{array}$ & $\begin{array}{l}\text { DOE Reference Model } \\
\text { (Medium Office) }\end{array}$ \\
\hline Fan motor parameters & $\begin{array}{l}\text { Fan motor electrical efficiency }=0.9(90 \%) \\
\text { Fan motor location }=1.0 \text { (inside air stream) }\end{array}$ & EEFG Tool \\
\hline Fan Pressure Rise & Zone/terminal fan pressure rise $=622 \mathrm{~Pa}$ & $\begin{array}{l}\text { DOE Reference Model } \\
\text { (Medium Office) }\end{array}$ \\
\hline HVAC sizing & $\begin{array}{l}\text { Cooling supply air temperature }=14^{\circ} \mathrm{C} \\
\text { Heating supply air temperature }=40^{\circ} \mathrm{C} \\
\text { Cooling supply air humidity ratio }=0.0085 \mathrm{H}_{2} \mathrm{O} / \mathrm{kg} \text {-air } \\
\text { Heating supply air humidity ratio }=0.0080 \mathrm{H}_{2} \mathrm{O} / \mathrm{kg} \text {-air }\end{array}$ & \\
\hline
\end{tabular}

The HVAC parameters in Table 5 are related to operational design of cycling system fans. Such components are assumed to be in continuous operation during occupied hours cycling during off-hours to meet loads imposed by set-back temperatures. Fan pressure rise levels are derived from models (with similar building size and HVAC zoning) generated by EEFG Tool. DOE Reference Models are utilized to provide fan operation and motor parameters. All types of building schedules pertaining to occupant density, activity rate, clothing level, lighting power density, equipment power density, air infiltration rate have 


\section{Karaguzel and Lam}

to be derived from DOE Reference Models due to the fact that such information cannot be found in related standards and proposed design specifications. Similar situation is observed for environmental control hourly schedules for heating and cooling set-point, setbacks and minimum ventilation air as well as HVAC system schedules such as fan, coil (heating, cooling), air handling unit and plant (e.g., boiler and chiller) availability schedules.

\subsection{Schematic Framework of Benchmark Model Development Process}

The baseline model development process for Building 661 retrofit case can be represented by schematic depiction with the network of data feed-in from previously identified information sources. The model development schema shown in Figure 2, identifies possible whole-building baseline model alternatives that can be considered throughout the study. Only the alternative models named "ASHRAE 90.1 2004 Compliant Model with ASHRAE Standard Envelope" is analyzed here as shown on the left hand side of the schema. The middle section includes an exhaustive list of input data categories (simulation model input parameters) with their sub-categories all of which are integral to a whole-building energy model. On the right hand side of the schema are possible information sources from which necessary model input data can be drawn. Information flows from "sources" to "sinks" (in this case modeling input data categories) are related to each other with path lines. A total of 10 links are created between baseline model alternatives and input data categories to cover all possible inputs. There are a total of 31 links between input data categories and information sources due to the consideration sub-categories (multiple sources can be used for a single category such as building envelope). The largest number of links for a single information source is observed for DOE Reference Models as 12 (38.7\% of all possible connections). This followed by ASHRAE 90.12004 standard with 11 links (35.4\% of total). On the other hand, EEFG Tool and ASHRAE 62.1 standard are individually used for $6.4 \%$ and $3.2 \%$ of possible information flows, respectively. Project documents and survey data source category is related to 4 links mainly for specification of contextual model data as well overall as building geometry (including windows and skylights). From the input data category point of view, building envelope includes the most diversified use of information sources ( 4 of 6 sources need to be engaged in the development process). Building envelope is followed by HVAC system, environmental controls, and building context with connections to at least 3 different information sources. Input categories of building geometry, thermal zones, occupancy inputs and operational schedules require single link to respective sources of information (DOE Reference Models for most of the input categories). Furthermore, input categories of lights and equipment, and service water heating have at least 2 different links to related information sources.

\section{CONCLUSIONS}

Through literature review, this paper first summarizes current methods of benchmarking energy performance of buildings for comprehensive retrofit projects and indicates the significance of whole-building modeling and simulation techniques in supporting the design decision making process. A baseline model development process for a retrofit case (Building 661, Navy Yard, Philadelphia, PA) is proposed so as to determine possible issues associated with unique condition of historic buildings which lack energy use/utility data, and without any proposed design specifications (to apply back-engineering for modeling input derivation). This analysis includes baseline model input data categorization, specification and explanation of possible information sources for data derivation as well as identification of specific input categories causing recourse to multiple information sources for model development. A schematic depiction of baseline model development process for the building case is also provided. From the analytical study, it is observed that:

- The lack of historical energy use data for retrofit projects prohibits utilization of statistical regression-based benchmarking methods based on existing energy data sets for characterization of significant determinants of energy consumption and prediction for unknown parameters. Similar situation is observed for calibration of computational model-based benchmarking methods. 


\section{Karaguzel and Lam}

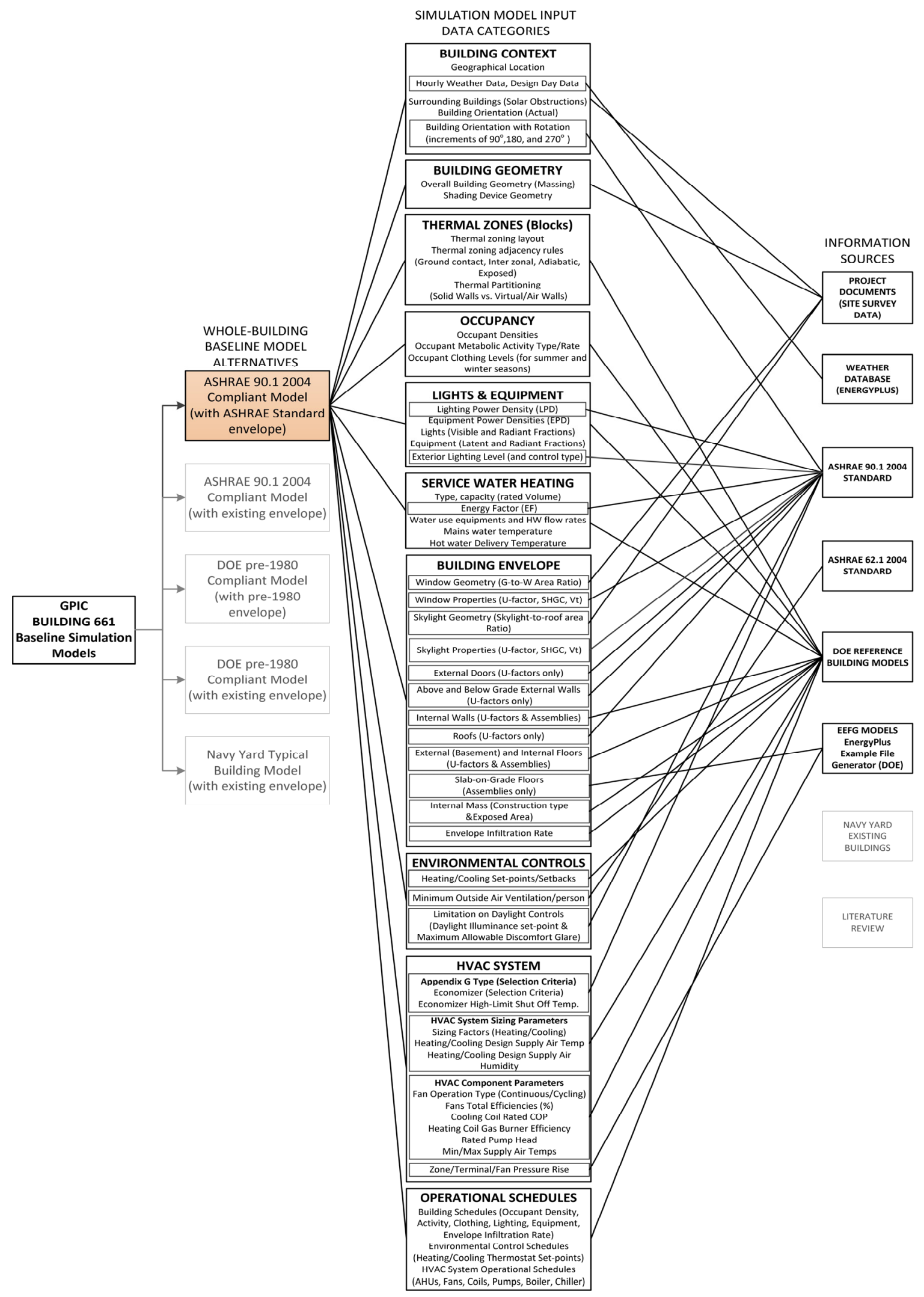

Figure 2: Schema of whole-building baseline model development process 


\section{Karaguzel and Lam}

- The use of DOE Reference Models in conjunction with related standards (ASHRAE 90.1 and 62.1) covers a majority of input data requirements. However, the use of external tools (EEFG Tool) as well as as-built project documentation and survey data is necessary for a complete baseline model.

- The largest number of information sources required to define a single input data category is observed for the category of building envelope which is followed by building context, environmental controls, HVAC system. Lack of guidance from standards is augmented for input categories of thermal zoning, occupancy, lights and equipment, operational schedules and operational schedules all of which requires back-engineering approach for their development processes.

This study forms the conceptual foundations of an automated whole-building simulation model development procedure where relevant input data encapsulated into generic informational infrastructure (such as XML - extensible markup language) are automatically populated and embedded into an integrated energy simulation tool (EnergyPlus) with little or no human interaction. Such an automation can decrease time and effort (in addition to human-based modeling flaws) spent during baseline model development process of an energy retrofit project of historic building cases.

\section{ACKNOWLEDGMENTS}

This study is supported by the Greater Philadelphia Innovation Cluster (GPIC) for Energy Efficient Buildings (a U.S. DOE Innovation Hub) project under Task 2 (Design Tools - Modeling).

\section{REFERENCES}

ASHRAE. 2004a. "ASHRAE Standard 62.1-2004: Ventilation for Acceptable Indoor Air Quality." ASHRAE Standing Standard Project Committee 62.1. Atlanta, Georgia.

ASHRAE. 2004b. "ASHRAE Standard 90.1-2004: Energy Standard for Buildings Except Low-Rise Residential Buildings." ASHRAE Standing Standard Project Committee 90.1. Atlanta, Georgia.

Chimack, M. J., C. E. Walker, and F. Franconi. 2001. "Determining Baseline Energy Consumption and Peak Cooling Loads of a 107-Year-Old Science Museum Using DOE 2.1E." In Proceedings of the Seventh International IBPSA Conference, 191-198. Rio de Janeiro, Brazil. International Building Performance Simulation Association. Chung, W., Y. V. Hui, and Y. M. Lam. 2006. "Benchmarking the Energy Efficiency of Commercial Buildings." Applied Energy 83:1-14.

Cort, K. A., J. A. Dirks, D. J. Hostick, D. B. Elliot. 2009. "Analyzing the Life Cycle Energy Savings of DOE-Supported Building Technologies.” Technical Report No. PNNL-18658, Pacific Northwest National Laboratory. Richland, Washington.

Denniston, S. 2010. "Toward a Future Model Energy Code for Existing and Historic Buildings." In Proceedings of the 2010 ACEEE Summer study on Energy Efficiency in Buildings, 8:88-99. Washington, DC: American Council for an Energy-Efficient Economy.DOE-HUB/GPIC (Department of Energy Hub - Greater Philadelphia Innovation Cluster) 2011. Greater Philadelphia Innovation Cluster for Energy Efficient Buildings. 2011. Accessed May 7. http://gpichub.org/.

Dong, B., S. E. Lee, and M. H. Sapar. 2005. "A Holistic Utility Bill Analysis Method for Baselining Whole Commercial Building Energy Consumption in Singapore." Energy and Buildings 37:167-174.

Fumo, N., P. Mago, and R. Luck. 2010. "Methodology to Estimate Energy Consumption Using EnergyPlus Benchmark Models." Energy and Buildings 42:2331-2337.

Hicks, T., and D. Clough. 1998. "The Energy Star Building Label: Building Performance through Benchmarking and Recognition." In Proceedings of the 1998 ACEEE Summer Study on Energy Efficiency in Buildings, 4:205-210. Washington DC: American Council for an Energy-Efficient Economy. 
IPMVP (International Performance Measurement and Verification Protocol). 2006. "Concepts and Options for Determining Energy Savings in New Construction Volume III: Applications.” Efficiency Valuation Organization (EVO). Accessed May 25.

http://www.evo-world.org/index.php?option=com_form\&form_id=13.

Kalay, Y. E. 1999. "Performance-Based Design.” Automation in Construction 8:395-409.

Olgyay, V., and C. Seruto. 2010. "Whole-Building Retrofits: A Gateway to Climate Stabilization." ASHRAE Transactions 116:1-8.

Merriam-Webster. 2011. "Online Dictionary and Thesaurus." Accessed May 25. http://www.merriamwebster.com/.

Pan, Y., Z. Huang, and G. Wu. 2007. "Calibrated Building Energy Simulation and its Application in a High-Rise Commercial Building in Shanghai." Energy and Buildings 39:651-657.

Sartor, D., A. Piette, and W. Tschudi. 2000. "Strategies for Energy Benchmarking in Cleanrooms and Laboratory-Type Facilities." Technical Report No. LBNL-45928, Lawrence Berkeley National Laboratory. Berkeley, California.

Sharp, T. 1996. "Energy Benchmarking in Commercial Office Buildings." In Proceedings of the 1996 ACEEE Summer Study on Energy Efficiency in Buildings, 4:321-329. Washington, DC: American Council for an Energy Efficient Economy.

U.S. DOE (Department of Energy). 2011. "Building Energy Data Book." Accessed May 1. http://buildingsdatabook.eren.doe.gov/.

U.S. DOE BTP (Building Technologies Program). 2011. "EnergyPlus v6.0 Energy Simulation Software.” Accessed May 1. http://apps1.eere.energy.gov/buildings/energyplus/

U.S. DOE EERE (Energy Efficiency and Renewable Energy Office). 2011. "Commercial Reference Building Models.” Accessed May 10.

http://www1.eere.energy.gov/buildings/commercial_initiative/new_construction.html.

U.S. DOE NREL (National Renewable Energy Laboratory). 2011. "EnergyPlus Example File Generator." Accessed May 5. http://apps1.eere.energy.gov/buildings/energyplus/cfm/inputs/index.cfm.

U.S. Environmental Protection Agency. 2011. "ENERGY STAR Benchmarking." Accessed May 20.http://www.energystar.gov/index.cfm?c=evaluate_performance.bus_portfoliomanager_benchmark ing

OMER TUGRUL KARAGUZEL is a Ph.D. candidate at the graduate program of Building Performance \& Diagnostics (BPD), Carnegie Mellon University, PA. He received his Master of Science degree on passive solar building energy systems from Middle East Technical University (METU), Turkey. He also had his B.Arch. degree from the same institution. He has 6 years of prior experience on design and education of environmentally sustainable architecture and 3 years of experience on building energy modeling and simulation. His current research interests are in simulation-based optimization of advanced solar facades with building integrated photovoltaics. His email address is okaraguz@andrew.cmu.edu.

KHEE POH LAM is a Professor of Architecture at School of Architecture, Carnegie Mellon University, PA. He teaches architectural design, building performance modeling, building controls and diagnostics, acoustics and lighting. His fields of research are in total building performance studies and the development of computational design support systems. His work has been widely published and he serves as a member of the Editorial Boards of the Journal of Building Performance Simulation (UK), and Building Simulation: An International Journal (China). He is a member of the US Energy Foundation Board of Directors. He actively works with their China Sustainable Energy Program on a range of activities including green building codes and standards and green design of various demonstration projects in China. He is also a building performance consultant for several major award winning projects in the private and public sectors in Singapore, and remains engaged in ongoing projects in the USA and Taiwan. He is currently. Visiting Professor at the Department of Architecture, Chinese University of Hong Kong. His email address is kplam@cmu.edu. 